\title{
Brute force effects of mass media presence and social media activity on electoral outcome
}

Kovic, Marko ; Rauchfleisch, Adrian ; Metag, Julia ; Caspar, Christian ; Szenogrady, Julian

\begin{abstract}
In this study, we analyze whether the mere volume of presence in mass media and the mere volume of activity on social media convey advantages to candidates in parliamentary elections. Based on the theoretical model of bounded rationality, we call these potential effects brute force effects. During the last month of the election campaign of the Swiss federal election of 2015, we tracked the presence of all 873 candidates in the canton of Zurich, the most populous canton, in a broad sample of mass media. Additionally, we tracked those candidates' activity on Facebook and Twitter. The results of our multilevel Bayesian estimates show that mass media presence has a consistent nontrivial impact on different aspects of electoral outcome. Furthermore, social media activity also has a nontrivial impact, but only in terms of resonance (reactions to candidates' social media activity). Overall, our results suggest that brute force effects of of mass media presence and social media activity can have substantial impact on voting behavior.
\end{abstract}

DOI: https://doi.org/10.1080/19331681.2017.1374228

Posted at the Zurich Open Repository and Archive, University of Zurich

ZORA URL: https://doi.org/10.5167/uzh-148327

Journal Article

Accepted Version

Originally published at:

Kovic, Marko; Rauchfleisch, Adrian; Metag, Julia; Caspar, Christian; Szenogrady, Julian (2017). Brute force effects of mass media presence and social media activity on electoral outcome. Journal of Information Technology Politics, 14(4):348-371.

DOI: https://doi.org/10.1080/19331681.2017.1374228 


\title{
Brute force effects of mass media presence and social media activity on electoral outcome
}

\author{
Marko Kovic ${ }^{\mathrm{a}}$, Adrian Rauchfleisch ${ }^{\mathrm{a}, \mathrm{b}}$, Julia Metag ${ }^{\mathrm{c}}$, Christian \\ Caspar $^{\mathrm{a}, \mathrm{d}}$, and Julian Szenogrady ${ }^{\mathrm{b}}$ \\ a ZIPAR - Zurich Institute of Public Affairs Research, Zurich, Switzerland. \\ ${ }^{\mathrm{b}}$ Institute of Mass Communication and Media Research, University of Zurich, \\ Switzerland. \\ ${ }^{\mathrm{c}}$ Department of Communication and Media Research, University of Fribourg, Switzerland. \\ ${ }_{\text {fög }}$ - Research Institute for the Public Sphere and Society, University of Zurich, \\ Switzerland.
}

July 14, 2017

\begin{abstract}
In this study, we analyze whether the mere volume of presence in mass media and the mere volume of activity on social media convey advantages to candidates in parliamentary elections. Based on the theoretical model of bounded rationality, we call these potential effects brute force effects. During the last month of the election campaign of the Swiss federal election of 2015, we have tracked the presence of all 873 candidates in the canton of Zurich, the most populous canton, in a broad sample of mass media. Additionally, we have tracked those candidates' activity on Facebook and Twitter. The results of our multilevel Bayesian estimates show that mass media presence has a consistent non-trivial impact on different aspects of electoral outcome. Furthermore, social media activity also has a non-trivial impact, but only in terms of resonance (reactions to candidates' social media activity). Overall, our results suggest that brute force effects of of mass media presence and social media activity can have substantial impact on voting behavior.
\end{abstract}




\section{Introduction: Mass media presence and social media activity as brute force effects}

To note that, during election times, public communication about the election campaign matters is a truism that verges on the trivial. From the point of view of the political actors who are seeking office, being present in the public discourse is quite obviously a goal - after all, political actors have to mobilize their supporters as well as persuade other potential voters in the hopes of turning them into supporters (Rohrschneider 2002; Nimmo 2001). From the voters' point of view, public communication about the campaign is welcome, because it provides them with information that is necessary in order for them to decide which candidates and parties are best aligned with their own preferences (Gelman and King 1993; K. M. Hansen and Pedersen 2014; Nadeau et al. 2008). From a systemic, democratic point of view, public discourse about electoral campaigns is welcome as well, because, ideally, some rational discourse about the quality of different policy proposals will take place (Habermas 2006).

Possibly for as long as modern representative democracy has existed, the most important venue of public communication during election campaigns have been professional mass media news outlets. Mass media do not, of course, exhaust the whole conceptual space of public communication, but functionally, they serve as a master forum (Ferree 2002, p. 10) where communication flows about relevant issues aggregate. In electoral campaigns, the master forum of the mass media plays a crucial role, not least because a large and relevant proportion of the electorate - essentially, what is sometimes referred to as the the median voter (Black 1948; Downs 1957) - can be addressed via mass media. Research on the role of news media during elections is plentiful, and a number of effects of news media coverage have been observed, mostly hovering around the questions of what and how the media report during electoral campaigns, and how that reporting impacts voter attitudes. Some prominent venues of research include research on the dynamics of agenda-setting and framing (Scheufele and Tewksbury 2007), research on the reputational consequences of news media reporting in the form of issue-ownership (Petrocik 1996), and research on the nature of the journalistic output in campaign times (Iyengar, Norpoth, and Hahn 2004). One potentially important aspect of the news media during elections, however, receives relatively little attention, as Hopmann, Vliegenthart, et al. (2010) note: The question whether the mere volume of candidate visibility, or presence, in the news media has an impact on electoral outcomes. To some degree, it is understandable that his question receives little scientific attention. While research on phenomena such as, for example, the aforementioned framing and issue ownership effects focuses on effects that are contingent on the properties of mass media output, possible effects of the sheer volume of mass media content seem less of a sophisticated effect.

The traditional news media are not the only venue of public communication in election times. Campaigning events, billboards (Seidman 2008), cold calling 
(Nickerson 2006; Nickerson 2007) and direct mail (Green and Gerber 2015) have long been, and still are, staple methods of campaigning. These venues of public campaign communication have been supplemented by social media. Social media, understood as Internet-based applications that allow for the creation and exchange of user-generated content (Kaplan and Haenlein 2010), provide candidates with the opportunity to reach significant parts of the public without there being gatekeepers, such as journalists, who wield veto power over the information flows and contents.

The goal of this study is to further explore whether the volume of candidate presence in traditional mass media and the volume of candidate activity on social media have an impact on candidates' electoral fortunes. We call the impact of mass media presence and of social media activity brute force effects. We analyze the brute force effects with the following two research questions:

- RQ1: Does candidates' presence in the mass media have an effect on their electoral success?

- RQ2: Does candidates' activity on social media have an effect on their electoral success?

We analyze these questions in the context of the 2015 Swiss federal election, which took place on October 18, 2015. Our study adds to the existing literature in three ways. First, we include not only social media in our study, but a rather large sample of traditional mass media as well, since mass media most certainly still matter. Second, we aim to embed our study in a broader theory of voter behavior. Third, the peculiarities of the Swiss electoral system are a very fertile ground for conducting this study, because the expected effects can be measured in great detail.

\section{Voter preferences and electoral campaigns}

Our overarching theoretical model of voters is one of rational voters. We believe that, generally, voters have preferences, and they act in accordance with their preferences so as to achieve what they want to achieve. This is, in a nutshell, the rational choice model of voting behavior (Shepsle 2010). But we don't believe that voters are perfectly rational in their behavior, and thus, we don't believe a model of perfect rational choice to be appropriate in the context of voting. Of course, the idea that a pure model of rational choice does not fit reality all that well is not new (Simon 1955). In contemporary research on rational choice, there is broad and uncontested consensus that the insights of behavioral economics (Mullainathan and Thaler 2000) about erroneous inference and decision-making do not represent a deviation from regular human cognition, but rather, they demonstrate that regular human cognition is fundamentally error prone.

Given such a behavioral economics view of human cognition, our understanding of voter behavior is one of bounded rationality (Jones 1999). Generally, voters are rational in that they have preferences and act in line with their preferences in the 
act of voting. But voters' cognitive apparatus makes use of cognitive heuristics to process information, to make inferences about the world, and to partly base decisions - specifically, the act of voting - on those heuristics.

There are many cognitive heuristics that affect inference- and decision. In the context of the present study, one particular heuristic is of interest: The so-called mere exposure effect (Zajonc 1968; Zajonc 2001; Harmon-Jones and Allen 2001; J. Hansen and Wänke 2009). The mere exposure effect describes the tendency for humans to develop a positive attitude towards information, objects or people merely by being exposed to that information, those objects, or those people. Mere exposure effects can manifest in many different contexts, not least in the context of elections (Verhulst, Lodge, and Lavine 2010). The concept of brute force effects of candidates' mass media presence and social media activity is simply a theoretical extension of the mere exposure effect in the context elections. If mere exposure increases familiarity, and with familiarity comes positive attitude, then, in the setting of elections, mere exposure should translate into positive electoral effects. This means that, with the concept of brute force effects, we are describing the expected empirical consequence of the mere exposure effect in the context of elections.

Our model of voting behavior can be summarized as a combination of rational and non-rational voting, whereby brute force effects form a subset of non-rational voting. We argue that non-rational voting, by which we mean voting that is not only a pure function of individual fixed preferences, is a large part of overall voting behavior. Brute force effects as the consequences of the mere exposure heuristic is a subset of non-rational voting. However, we believe that brute force effects form only a minor part of non-rational voting. This rationale is depicted visually in Figure 1.

Figure 1: Visual depiction of brute force effects within the sets of rational and nonrational voting.

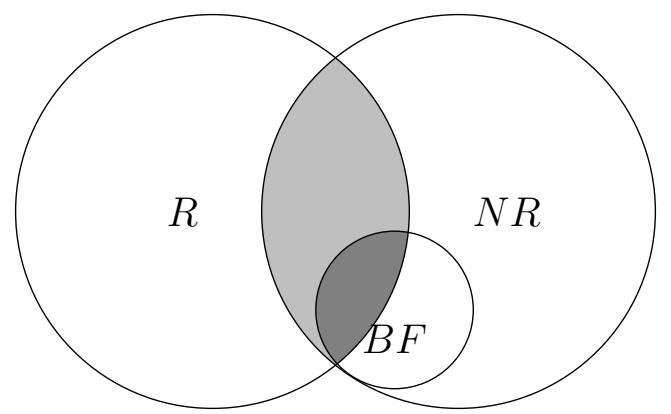

Explanation: $R$ stands for the set of rational voting, $N R$ for the set of non-rational voting, and $B F$ for the subset of brute force effects.

There are two main sets in Figure 1, the set of rational voting and the set of non-rational voting. There is an area of overlap among those sets (light gray area). 
This overlap symbolizes the fact that there is not only purely rational and purely non-rational voting, but also voting that is rational in principle, but affected by non-rational mechanisms, such as heuristics. Brute force effects are a subset of nonrational voting - all voting affected by brute force effects is non-rational. However, not all voting affected by brute force effects is necessarily purely non-rational. It is also possible that voting that is rational in principle is affected by brute force effects (dark gray area). The visualization in Figure 1 does not empirically quantify the size of brute force effects, but is contains information that expresses our assumption about the magnitude of brute force effects. Brute force effects, we believe, are only a minor part of all non-rational voting. Furthermore, we believe that brute force effects do not have to be total and exclusive effects: Voters can very well be rational for the most part and be affected by brute force effects in addition to their rational, preferential voting.

Overall, then, we posit that brute force effects of candidates' mass media presence and social media activity are only a minor part of overall voting behavior. We do so for two reasons. First, as we argue above, brute force effects are only a subset of non-rational behavior. Furthermore, there is broad consensus that media effects do exist, but that they are generally small effects, if not minimal ones (Bennett and Iyengar 2008). Our assumption about the magnitude of brute force effects, then, is both conceptually and empirically motivated.

\subsection{Existing research}

There is a growing body of research that is interested in finding out how social media is used in electoral campaigns, and what results from it (Kreiss 2015; K. M. Hansen and Kosiara-Pedersen 2014). Social media tends to have a vox populi signaling effect, in that what is visible on social media is presumed to represent public opinion. For example, journalists are prone to this kind of heuristic (Anstead and O'Loughlin 2015), whereby anecdotal evidence is generalized as indicative of public opinion.

However, more systematic analyses of the connection between social media and elections have yielded more robust and relevant results. One prominent question that has been explored in recent years is whether data from social media has any form of potential predictive power for electoral outcomes (Metaxas, Mustafaraj, and D. Gayo-Avello 2011; Daniel Gayo-Avello 2012; Daniel Gayo-Avello 2013). Even though the present evidence for the predictive power of social media is far from conclusive, the general idea is not without merit. Samples of social media users can be thought of as an extreme form of non-probability sampling (Baker et al. 2013). This will become ever more the case as social media penetration rates continue to climb and encompass most population segments and strata.

The literature on predictive power of social media is certainly relevant in and of itself, but it is only tangentially related to the concept of brute force effects. However, there actually is a small, less prominent body of literature that has explored potential brute force effects of social media activity on electoral outcomes. 
These studies did not operate with the concept of brute force effects, but what they analyzed are possible brute force effects as we define them in this study. The results of those studies are generally mixed, as Jungherr (2016) summarizes. Some studies find no effect at all (Marcinkowski and Metag 2013; Jungherr 2013). Other studies do find an effect, but a rather modest one, in that the relevant question is not so much how active candidates are on social media, but rather whether they are present on social media at all (Gibson and McAllister 2011; Kruikemeier 2014). A number of studies report that the degree of activity on social media, either directly by candidates themselves or indirectly through other users reacting to candidates, matters (Spierings and Jacobs 2014; Jacobs and Spierings 2016; DiGrazia et al. 2013).

These studies, however, have two shortcomings. First, they analyze only the social media platform Twitter. Twitter matters, of course, but using Twitter as a pars pro toto for social media in general is, at the very least, not something that is self-explanatorily plausible. Second, those studies either completely disregard traditional mass media, or, if they don't, they work yet again with a pars pro toto strategy by generalizing a single media outlet as representative for all media outlets in the given polity. With the present study, we aim to continue the valuable research trajectory outlined by these studies, and we take steps to address the two shortcomings in the literature.

\subsection{The Swiss electoral system: A precise seismograph of voter preferences}

The Swiss federal parliament consists of two chambers, an upper and a lower house. The upper house consists of 46 members who are representatives of the Swiss cantons, polities similar to states in the United States. Members of the upper house are elected by majority vote. The lower house consists of 200 members who are elected by proportional vote. For the lower house election, Cantons are the voting districts, just as they are for the upper house elections. In the present study, we are interested in the lower house elections that are carried out by proportional vote.

The election of the Swiss federal lower house is carried out both on a party and individual candidate level. The starting point for voters to vote are individual voting lists that, by and large, correspond to different political parties. Every voter has the right to vote for one voting list. In principle, the amount of voting lists per voting district, i.e., per canton, is not limited. In 20 of the 26 Swiss cantons, any political party, loose group or even singular candidate can register as a voting list if they manage to gather enough signatures in a petition prior to the election ${ }^{1}$. In the remaining six small cantons that only have one seat in the lower house, no signatures have to be collected for candidacy eligibility ${ }^{2}$. The majority of the

\footnotetext{
${ }^{1}$ The number of signatures required for a candidacy varies according to the cantonal population sizes, but does not exceed the relatively low amount of 400 .

${ }^{2}$ In four of these small cantons, any one Swiss citizen from the respective canton is eligible to
} 
seats of the lower house, 194 out of 200, are allocated in voting districts where proportional voting actually takes place $^{3}$. The Swiss proportional electoral system, however, is not limiting to choosing only among the voting lists (i.e., among the parties). The voting lists actually only contain the pool of registered candidates, and voters are free to choose among those candidates whatever way they wish. This means that voters are allowed to remove candidates from a list, add candidates from other lists, or even give individual candidates two votes. The latter procedure is referred to as "cumulation", and adding candidates from other lists is known as "panachage". Cumulation and panachage give voters great flexibility, but those procedures are limited. First, only candidates who are within the overall pool of pre-registered candidates are eligible for cumulation and panachage. Second, a single voter is only allowed to cumulate two votes per candidate. That means that on a voter's voting list, the same candidate name can only appear twice. Furthermore, the maximum number of candidates per voting list as well as the total amount of votes a voter allocates is fixed because the number of slots on voting lists is fixed. For example, in the canton of Zurich, the 2015 voting lists contained 35 slots, because the canton of Zurich occupies 35 seats in the lower house of parliament. Therefore, a voter in the 2015 election could vote for at most 35 candidates. It was not possible to add more than 35 candidates through panachage, and it was not possible to cumulate a vote for a candidate more than once. By cumulating a vote for a candidate, two of the 35 slots on the voting list were allocated to that candidate.

The Swiss electoral system for proportional allocation of seats to the lower house, thus, allows voters to express their preferences in a very precise manner. Accordingly, the outcome of the election reflects this, metaphorically speaking, seismographic quality of the electoral system. Not only is it known which candidates are elected to the lower house and how many votes the candidates receive, but there is also data on the amount of panachage as well as the amount of cumulation votes each candidate receives. From the point of view of candidates, then, there are four natural outcome variable of the lower house elections: Being elected into office or not, the total amount of votes received, the amount of panachage votes, and, finally, the amount of cumulation votes.

\subsection{Hypotheses}

In the preceding sections, we have, first, explained our voting behavior model of bounded rationality with relation to brute force effects of candidates' mass media presence and social media activity. Second, we have briefly described the nature of the Swiss electoral system of the lower house elections. If we apply the model of brute force effects to aggregate electoral behavior with regards to the lower

\footnotetext{
be elected into the lower house, even without prior official registration of the candidacy

${ }^{3}$ In the six small cantons with only one seat per canton, the election, naturally, defaults to a majority vote
} 
house elections, there are four outcome variables where brute force effects might, in principle, materialize: The probability for a candidate to win a seat, the total amount of votes a candidate receives, the amount of panachage votes a candidates receives, and the amount of cumulation votes a candidate receives.

We assume that brute force effects are, generally, weak effects. This means that the rational components of voting behavior, as well as non-rational components other than brute force effects, will probably outweigh brute force effects themselves. We do not expect brute force effects to be decisive factors neither for the probability of a candidate receiving a seat in the lower house, nor for the total amount of votes a candidate receives. We express these two expectations with the hypotheses H1 and $\mathrm{H} 2$ :

- Hypothesis H1: Brute force effects have no substantial impact on a candidate's probability of being elected into the lower house.

- Hypothesis H2: Brute force effects have no substantial impact on the total amount of votes a candidate receives.

In hypotheses $\mathrm{H} 1$ and $\mathrm{H} 2$, we are deliberately referring to substantial impact instead of something like "no impact". Assuming no effect means expressing a belief in a null model, and we don't think that null models are plausible under any reasonable set of assumptions for the purpose of this study. What is interesting and epistemically more plausible is analyzing what effects actually exist, and how meaningful they are for the given research questions.

We consider brute force effects to have no substantial impact on election chances as well as on the total amount of votes. However, we do think that brute force effects can have non-trivial impact on the other two outcome measures of electoral success, the amount of panachage and cumulation votes. In the model of bounded voter rationality, we expect voter preferences to be, for the most part, fixed. But we do believe that brute force effects play a role nonetheless: They have a mobilizing effect on voters' preferences on individual candidates. This means that voters have, in principle, preferences about who they want to vote for, and the brute force of candidate mass media presence and social media activity can "nudge" voters into expressing those preferences. Functionally, this nudging function is the same as nudging in the sense of choice architecture (Sunstein 2014; Thaler and Sunstein 2009), but conceptually, of course, it only partly is (Brute force effects are "side effects", not the primary intention, of mass media presence and social media activity.).

We express the expectation of brute force effects as mobilizing nudges in hypotheses H3 and H4.

- Hypothesis H3: Brute force effects have a substantial impact on a candidate's panachage votes.

- Hypothesis H4$_{4}$ : Brute force effects have a substantial impact on a candidate's cumulation votes. 
In hypotheses $\mathrm{H} 1$ to $\mathrm{H} 4$, we have expressed our expectations regarding the impact of the brute force effect of candidates' mass media presence in conjunction with the brute force effect of candidates' social media activity. But we don't believe that those two effects only occur together, but rather, that they are seperate effects. In hypothesis $\mathrm{H} 5$, we express our expectation that, overall, one effect is stronger than the other:

- Hypothesis H5: The brute force effect of mass media presence is stronger than the brute force effect of social media activity.

Even though social media are used ever more widely, mass media are still, as we argue in the introduction, a public master forum. Mass media reach many parts of the public, and thus, candidates' mass media presence does as well. In contrast, the candidates' audience on social media is much more fragmented and self-selected (Prior 2007). This means, in effect, that voters are more likely to notice candidates in mass media serendipitously, while they notice them on social media because they have already expressed interest in some candidates by "following" their social media profiles. From the candidates' point of view, mass media presence will simply reach more people than social media activity.

\section{Data and methods}

\subsection{Data collection}

We analyze the final campaigning phase of the 2015 Swiss federal election in this study. The elections took place on October 18, 2015, and we are analyzing the period from September 19 up to and including October 17. For this time period of the final four weeks, we collected data on candidates' mass media presence as well as their social media activity. The data for the dependent variables in this study - whether a candidate was elected; total number of votes per candidate; panachage votes per candidate, and cumulation votes per candidate - is provided by the cantonal statistical office of Zurich.

Table 1: Dependent variables for the present study.

\begin{tabular}{|c|c|c|}
\hline Variable & mean & $\mathrm{SD}$ \\
\hline elected (yes/no) & - & - \\
\hline total votes & 16588.1 & 30973.0 \\
\hline panachage votes & 8456.3 & 16795.2 \\
\hline cumulation votes & s 7399.9 & 15175.3 \\
\hline
\end{tabular}

Each variable is used as the dependent variable in one of the four models that are estimated.

The research units for this study are the candidates for the lower house of the Swiss parliament in the canton of Zurich. Zurich is the largest voting district in 
Switzerland, because it is the largest canton in terms of population size. In the canton of Zurich, there were 35 different voting lists ${ }^{4}$ with a total of 873 candidates. We tracked the mass media presence as well as the social media activity of all 873 candidates in the canton of Zurich.

The main predictors in the present study are candidates' presence in mass media and candidates' activity on social media. The mass media presence of the candidates is a fairly straightforward variable: We count how often any one candidate has been present in newspaper articles, in segments of television news shows or in segments of radio shows between September 16 and October 172015. The media sample that we analyzed is summarized in Table 8. We have performed an automated content analysis within the statistical environment $\mathrm{R}$ ( $\mathrm{R}$ Core Team 2015) on a sample of 11 newspapers, three television news shows and two radio news shows. Additionally, we have manually counted the occurrence of candidates in three television news shows on a regional television channel. We did not calculate an intercoder reliability for these three shows because counting occurrences was very simple: Two of the shows in question ${ }^{5}$ are political talk shows where two to four guests appear and stay for the whole show. It was therefore very simple to identify candidates. The third show is a short news show ${ }^{6}$ of around 15 Minutes in length for which we had segment-by-segment video data available. This also made counting occurrences manually very simple.

When a candidate was mentioned, quoted or had a direct appearance (in the case of newspaper interviews and studio appearances on television news shows) once or several times in an article or a broadcasting show segment, we counted that as one occurrence. However, if a candidate was mentioned in, for example, several separate newspaper articles in the same newspaper on the same day, we counted that as multiple occurrences. For the radio and television news shows, an explicit appearance of a candidate combined with with an explicit mention of that candidate's name was a necessary condition for counting an occurrence ${ }^{7}$. The media sample for this study consists of titles that have a general, broad focus for the whole German-speaking part of Switzerland as well as titles that are of very regional character and mostly have a cantonal audience. In total, our media sample resulted in 125 occurrences of candidates in broadcasting media, and 1460

\footnotetext{
${ }^{4}$ Most of those voting lists correspond to a political party. However, a few voting lists did not directly represent political parties, but different types of political groups, some of them only semi-serious, such as the "Anti PowerPoint Party". Any one individual can form a voting list and become a candidate in the canton of Zurich if they manage to collect 400 signatures from Swiss citizens living in the canton of Zurich.

5"TalkTäglich" and "SonnTalk"

6"ZüriNews"

${ }^{7}$ We had access to the official database of the Swiss Broadcasting Corporation. For each segment in the news, the mentioned and quoted politicians are listed in the database. For newspapers, we automatically extracted all politicians. For common names and all politicians with more than ten mentions, we checked manually for false positives and subtracted them. The newspaper articles were downloaded from the comprehensive Swiss Media Database (Schweizerische Mediendatenbank).
} 
occurrences of candidates in newspapers.

We measure candidates' social media activity in a fairly comprehensive manner. First, contrary to many studies interested in social media and politics, we are not analyzing solely Twitter as a pars pro toto for social media, but additionally, we are analyzing candidates' activity on Facebook as well. Second, we are interested in two conceptual dimensions of candidate activity on each of those two platforms: Direct activity by candidates and candidate resonance. Direct activity is that kind of activity in which candidates directly take some action themselves. On Facebook, direct activity is either posting some content on one's wall, or sharing some other content on one's wall. Direct activity on Twitter is very similar: Candidates can either directly "tweet" themselves, or "retweet" some other tweets. The dimension of resonance is social media activity that is not initiated by candidates themselves, but which can make candidates more visible. On Facebook, resonance consists of other users liking, commenting on and sharing posts by candidates. Similarly, resonance on Twitter consists of other users liking, retweeting or replying to candidates tweets. To measure the resonance on Twitter, we tracked the user handles of all politicians to capture the number of replies a politician received. The number of received retweets and likes (favorites) could be accessed over the candidates' wall. The different components of social media activity are summarized in Table 2 .

Table 2: Components of social media activity.

\begin{tabular}{llll}
\hline Platform & Variable & Component & Type \\
\hline \multirow{2}{*}{ Facebook } & direct activity & posts (incl. shares) & count \\
\cline { 2 - 4 } & resonance & likes & count \\
& & comments & count \\
& & shares & count \\
\hline \multirow{2}{*}{ Twitter } & direct activity & tweets (incl. retweets) & count \\
\cline { 2 - 4 } & resonance & likes & count \\
& & retweets & count \\
& & replies & count \\
\hline
\end{tabular}

In order to collect social media data, we proceeded in two steps: First, we manually identified candidates' Twitter accounts and Facebook pages, and second, we automatically extracted data from those accounts and pages. For Twitter, we manually checked for every one of the 873 candidates whether a Twitter account exists for them. The criteria applied for identifying Twitter accounts are the following:

- A candidate's first and last name had to be present.

- In addition, at least one of the following additional conditions had to be satisfied: 
- Their political affiliation was mentioned in their Twitter profile.

- They tweeted about their political affiliation in the analyzed time period.

The identification of candidates' Facebook pages was similar. We manually searched for public Facebook pages of all 873 candidates. The identification criteria for Facebook pages and profiles are the same as the above ones for Twitter, only applied to Facebook. In total, 282 candidates had a Twitter account, and 138 candidates had a Facebook page.

We downloaded candidates' tweets from their user walls in an automated fashion within the computational environment R (R Core Team 2015). Furthermore, we regularly searched for all Twitter handles through the Twitter Search API in order to capture all replies to candidates' tweets. Using this approach, we were able to avoid issues that arise when using the Twitter Stream API (Bessi and Ferrara 2016). With the help of regex functions, we extracted only the replies to tweets by candidates, and we filtered out mere mentions of candidates that are not replies to candidates' tweets. With this approach, it was possible to compare the Twitter data to the Facebook data, since the data from the Facebook pages downloaded via the Facebook API does not contain information about mentions elsewhere of Facebook.

Overall, we are using six variables as independent variables of mass media presence and of social media activity. Two of those independent variables are related to mass media presence: The number of candidate occurrences in newspapers, and the number of candidate occurrsences in broadcast news shows. For social media predictors, we end up with four variables: One variable of direct activity and one of resonance for Facebook and Twitter each. The two variables of direct activity on social media are simply the counts of candidates' Facebook posts (including shares) and Twitter tweets (including retweets). The two variables of social media resonance are composite variables. For Facebook, they are the sum of the counts of likes, comments and shares by other Facebook users. For Twitter, they are the sum of the counts of likes, retweets and replies by other Twitter users. In the time period covered by this study, the candidates have created 1595 posts on Facebook and received 49869 resonance actions on their posts, and they have tweeted 7036 times and received 15887 resonance actions on their tweets.

In addition to two variables for mass media presence and the four variables for social media activity, we have collected additional data about the individual candidates. These additional independent variables are summarized in Table 3, together with the variables for social media activity.

Candidates' gender (Dolan 2008; Mcdermott 1998) and age (L. Sigelman and C. K. Sigelman 1982; Piliavin 1987) are variables that have been found to possibly play a role in elections as a type of non-rational heuristic. The electoral advantage of incumbents has been observed for some time and in different contexts (Erikson 1971; Alford and Hibbing 1981; Hogan 2004; Smith 2013; Ansolabehere and Snyder 2002). The voting list rank is a variable that captures the name order on the voting 
Table 3: List of independent variables.

\begin{tabular}{llllc}
\hline Variable & Type & Level & mean & SD \\
\hline gender & nominal & individual & - & \\
age & metric & individual & 44.6 & 15.2 \\
incumbency & nominal & individual & - & \\
voting list rank & ordinal & individual & 17.2 & 10.1 \\
voting list & nominal & group & - & \\
\hline Presence - newspapers & count & individual & 1.7 & 5.3 \\
Presence - broadcasting & count & individual & 0.1 & 0.9 \\
\hline Facebook - direct activity & count & individual & 1.8 & 7.9 \\
Twitter - direct activity & count & individual & 8.1 & 44.0 \\
Facebook - resonance & count & individual & 57.1 & 555.1 \\
Twitter - resonance & count & individual & 18.2 & 109.0 \\
\hline
\end{tabular}

lists. Name order has been found to have a non-trivial effect on voting outcomes (Ho and Imai 2008; Koppell and Steen 2004; Miller and Krosnick 1998). Name order effects are a very clear type of non-rational, heuristic driven voting behavior. The voting list variable is included in order to denote the group level variable for the multilevel modeling strategy (subsection 3.2).

\subsection{Data analysis}

The data as described in subsection 3.1 is of a particular structure. We have collected data on 873 candidates, and those candidates are members of 35 different voting lists. Our data, therefore, has a natural multilevel structure to it. Of course, the data analysis strategy should not be determined only by "accidental" properties of the data at hand, but it should be informed by epistemically reasonable assumptions. We believe our assumptions meet this requirement. The 35 different voting lists represent a wide range of parties, from relatively large ones that have been present in the Swiss federal lower house for decades, to very minor parties and groups that are not very well known. If we pooled all candidates together, we would be committing a rather grave base-rate fallacy (Bar-Hillel 1980): Given our prior knowledge on, for example, how well different political parties did in the last elections of 2011, it would be fairly irrational to assume that in this election, candidates of all parties would have an equal base-rate probability of being elected. For this reason, we are modeling our estimates as multilevel models with varying intercepts: We want to estimate effects of the predictors summarized in Table 3 given our strong expectation that not all parties, i.e., not all voting lists, would do equally well absent all predictors. In other words, we believe that voters have preferences, and those preferences, in the sense of rational voting, mostly determine the electoral outcome, and not our set of independent variables. All of this is simply a consequence of our theoretical understanding of voting behavior as explicated in 
section 1 .

We conduct the data analysis as Bayesian multilevel models using Stan (Carpenter et al. 2017) called via the package brms (Bürkner 2017) from within the computational environment $\mathrm{R}$ ( $\mathrm{R}$ Core Team 2015). We are using a Bayesian procedure for practical as well as philosophical reasons. Practically, Bayesian regression models perform better than frequentist regression models when the data in question has a multilevel structure (Browne and Draper 2006; Gelman and Hill 2006; Stegmueller 2013; Bryan and Jenkins 2016). Philosophically, the beliefs that are expressed via Bayesian models and the results that Bayesian models produce are more closely aligned to our actual beliefs and our interpretation of parameter estimates than is the case with frequentist models (Morey et al. 2016).

We estimate four models, corresponding to the four dependent variables of interest: Being elected, the total amount of votes, the amount of cumulation votes, and the amount of panachage votes. In the first of those models, the dependent variable is dichotomous. The model we estimate is the following one:

$$
\begin{gathered}
y_{i, j} \sim \operatorname{Bernoulli}(\mu) \\
\mu=\operatorname{logit}\left(\alpha_{i, j}+\beta_{i} x_{i}\right) \\
\alpha_{i, j} \sim \mathcal{N}\left(\alpha_{i}, \tau\right) \\
\alpha_{i} \sim \mathcal{N}(0,5) \\
\tau \sim \operatorname{Cauchy}(0,2.5) \\
\beta_{i} \sim \mathcal{N}(0,5)
\end{gathered}
$$

In this model, $i$ stands for the level of the individual candidate, and $j$ denotes the group level variable, the voting list. We estimate the other three models in the following manner:

$$
\begin{gathered}
y_{i, j} \sim t(\mu, \sigma, \nu) \\
\mu=\alpha_{i, j}+\beta_{i} x_{i} \\
\alpha_{i, j} \sim \mathcal{N}\left(\alpha_{i}, \tau\right) \\
\alpha_{i} \sim \mathcal{N}(0,10000) \\
\tau \sim \operatorname{Cauchy}(0,2.5) \\
\beta_{i} \sim \mathcal{N}(0,10000) \\
\sigma \sim \operatorname{Cauchy}(0,2.5) \\
\nu \sim \operatorname{Gamma}(2,0.1)
\end{gathered}
$$

For the parameter estimates in all models, we apply only vaguely informative priors. Even though we have suspicions about the model parameters - hence our 
hypotheses -, we do not think that those suspicions rise to the level of information that should be included in the model as prior information.

In our latter three linear models, we do not model the noise distribution as a normal distribution, but rather as a student's t distribution (Lange, Little, and Taylor 1989; Zhang et al. 2013). While the normal distribution is computationally simpler and, generally, more often used in regression modeling than the t distribution, the $t$ distribution has the advantage of being more robust against outliers (Kruschke 2014). When using the t distribution, it is necessary to specify its scale parameter $\nu$ (read "nu"). We do not give that parameter a fixed value, but, again, vague priors, as suggested by Juárez and Steel (2010).

Before estimating the models, we have standardized all independent variables that are not nominal by re-scaling it relative to their mean and standard deviation. Doing so has two advantages. First, rescaling the data makes the MCMC sampling more efficient. Second, the results become a little more meaningful: The parameter estimates indicate the effect that an independent variable in the model has when it changes by one standard deviation.

An important component of Bayesian estimation is deciding when to stop drawing samples and assume that the stationary distribution of the samples drawn approximates the posterior distribution. Our sampling strategy is two-fold. First, we report the potential scale reduction factors (Gelman and Rubin 1992) for all estimates, with the goal that $\hat{R}$ (for the sake of brevity, the potential scale reduction factor is denoted as $\hat{R}$ ) be close to 1 . Second, we present the posterior distribution in visual form in Appendix B in the appendix. A visual inspection can give additional insight into how well the different sampling chains converged.

For all models, we have drawn samples from four sampling chains. For each chain, we drew 2000 warmup iterations and 2000 sampling iterations. This modest amount of samples proved good enough for all models except one: For the model of hypothesis 4 where the number of cumulation votes is the dependent variable, we drew 3000 warmup iterations and 3000 sampling iterations. This increase in iterations yielded an acceptable level of convergence.

\section{Results}

In the following subsection, we present the estimation results for the four models of interest. For the hypotheses one to four, one model per hypothesis was estimated. We present the results in tabular form. Graphical summaries of the posterior distributions of the model estimates are presented in Appendix B.

\subsection{Hypothesis H1: Being elected into office}

For the first hypothesis, the dependent variable is dichotomous: Either a candidate is elected into office or not. The estimation results for the first model are summarized in Table 4. 
Table 4: Estimates of the first model. The dependent variable is the dichotomous election outcome of being elected or not.

\begin{tabular}{lrccc}
\hline Parameter & Mean & $2.5 \%$ quantile & $97.5 \%$ quantile & $\hat{R}$ \\
\hline Presence - newspapers & 1.19 & 0.54 & 1.98 & 1.00 \\
Presence - broadcasting & -0.10 & -0.68 & 0.56 & 1.00 \\
Activity - Facebook & -0.24 & -0.88 & 0.38 & 1.00 \\
Resonance - Facebook & 0.58 & -0.28 & 1.61 & 1.00 \\
Activity - Twitter & -0.72 & -2.54 & 0.29 & 1.00 \\
Resonance Twitter & 0.68 & 0.09 & 1.59 & 1.00 \\
Voting list rank & -1.10 & -2.49 & 0.00 & 1.00 \\
Incumbency & 4.08 & 2.11 & 6.18 & 1.00 \\
Age & 0.15 & -0.72 & 1.09 & 1.00 \\
Gender (female) & 2.02 & 0.47 & 3.81 & 1.00 \\
\hline
\end{tabular}

Note: The range between the $2.5 \%$ and $97.5 \%$ quantiles is the so-called $95 \%$ credible interval (CI). Given the data, there is a $95 \%$ probability that the parameter of interest lies in this range. Credible intervals are not the same as frequentist confidence intervals; the latter are oftentimes, incorrectly, interpreted as the former (Hoekstra et al. 2014).

The interpretation of the results is not directly intuitive, because the reported values are log odds. Nonetheless, it is immediately visible that there seem to be only a few estimates that are of practical relevance. The strongest effect on display is incumbency: If a candidate is an incumbent, that translates into a log odds of 4.08. Or, converted into an odds ratio by means of exponentiation: If a candidate is an incumbent, his or her odds of being elected are around 59 times higher than if they weren't an incumbent. Of the 873 candidates, 29 were incumbents. Of those 29, 24 got reelected - and only 11 of the 844 other, non-incumbent candidates got elected. The second effect of practical importance is sex: Female candidates are more likely to be elected than male ones, with log odds of 2.02, which translates to an odds ratio of about 7.5. Finally, presence in newspapers as an effect of 1.19, which translates into an odds ratio of 3.3. This means that one standard deviation of newspaper presence, presence 5.3 articles, has a non-negligible impact on being elected.

Overall, the first hypothesis is only partly supported. Contrary to the hypothesis, one aspect of brute force effects, the presence in newspapers, does have a positive non-negligible impact. Even though the effect is rather small, it cannot be ignored.

Overall, hypothesis H1 is only partly supported by the evidence. The effects of presence in broadcasting media, social media activity and social media resonance are all either small, inconsistent, or both. Presence in newspapers, however, is not: Being present in a newspaper article increases a candidate's odds of being elected to around 1.27; this effects posterior distribution lies almost completely in the positive range. 


\subsection{Hypothesis H2: Total amount of votes}

For the second hypothesis, the dependent variable is the total amount of votes. The summary of the model estimates that tests hypothesis H2 is reported in Table 5.

Table 5: Estimates of the second model. The dependent variable is the total amount of votes.

\begin{tabular}{lrccc}
\hline Parameter & Mean & $2.5 \%$ quantile & $97.5 \%$ quantile & $\hat{R}$ \\
\hline Presence - newspapers & 714.69 & 492.91 & 936.33 & 1.00 \\
Presence - broadcasting & 345.04 & -30.04 & 604.57 & 1.00 \\
Activity - Facebook & -63.73 & -132.59 & 18.09 & 1.00 \\
Resonance - Facebook & 1213.55 & 1084.55 & 1458.07 & 1.02 \\
Activity - Twitter & 38.35 & -129.70 & 246.29 & 1.00 \\
Resonance - Twitter & -9.48 & -187.67 & 206.69 & 1.00 \\
Voting list rank & -210.21 & -244.47 & -176.26 & 1.00 \\
Incumbency & 17012.03 & 15969.69 & 18029.76 & 1.00 \\
Age & -9.21 & -43.03 & 25.07 & 1.00 \\
Gender (female) & 16.88 & -42.00 & 78.15 & 1.00 \\
\hline
\end{tabular}

Note: The range between the $2.5 \%$ and $97.5 \%$ quantiles is the so-called $95 \%$ credible interval (CI). Given the data, there is a $95 \%$ probability that the parameter of interest lies in this range.

One estimate is immediately striking: If a candidate is an incumbent, he or she will receive, on average, an additional 17012 votes. This finding goes hand in hand with the one reported for the odds of being elected - there seems to be a strong incumbency bonus in the Swiss lower house elections. A second noticeable effect is Facebook resonance. An increase in one standard deviation of resonance, 555.1, translates into an average of some additional 1213 votes. Presence in broadcasting and in newspapers both have positive effects. An increase in one standard deviation of broadcasting presence, 0.9 , translates into an average of around 345 additional votes. However, the $95 \%$ credible interval does not lie wholly in the positive region; the posterior distribution's lower end dips slightly into the negative range. An increase in one standard deviation of newspaper presence, 5.3, translate into some 715 additional votes, on average. The effect of the voting list rank is slightly negative; the lower the candidates are on the voting list, the fewer votes they receive.

Overall, hypothesis 2 is only partly supported. The average amount of votes a candidate received is around 16500, with a standard deviation of about 30900 . In light of these magnitudes, the brute force effects are, contrary to our expectation, partly substantial. An increase in one standard deviation in newspaper presence results in an average of about 750 additional votes, and an increase in one standard deviation of Facebook resonance results in around 1213 additional votes - both of 
these effects are non-trivial.

\subsection{Hypothesis H3: Amount of panachage votes}

In hypothesis $\mathrm{H} 3$, we posit that mass media presence and social media activity will increase the amount of panachage votes a candidate receives. The results of the estimation for this hypothesis are summarized in Table 6.

Table 6: Estimates of the third model. The dependent variable is the amount of panachage votes.

\begin{tabular}{lrccc}
\hline Parameter & Mean & $2.5 \%$ quantile & $97.5 \%$ quantile & $\hat{R}$ \\
\hline Presence - newspapers & 441.39 & 328.58 & 541.59 & 1.00 \\
Presence - broadcasting & 69.28 & -14.45 & 139.56 & 1.00 \\
Activity - Facebook & -10.50 & -40.82 & 23.26 & 1.00 \\
Resonance - Facebook & 178.21 & 8.89 & 302.81 & 1.01 \\
Activity - Twitter & 8.81 & -22.45 & 71.55 & 1.00 \\
Resonance - Twitter & -1.30 & -36.29 & 29.27 & 1.00 \\
Voting list rank & -80.82 & -97.89 & -64.35 & 1.00 \\
Incumbency & 6499.10 & 4852.06 & 8096.97 & 1.02 \\
Age & -7.43 & -24.39 & 9.46 & 1.00 \\
Gender (female) & 25.15 & -4.79 & 56.47 & 1.00 \\
\hline
\end{tabular}

Note: The range between the $2.5 \%$ and $97.5 \%$ quantiles is the so-called $95 \%$ credible interval (CI). Given the data, there is a 95\% probability that the parameter of interest lies in this range.

Once again, the strongest effect by far is a candidate's incumbency status: On average, incumbents receive around 6500 more panachage votes than nonincumbents. The second most notable effect is presence in newspapers. An increase in one standard deviation of newspaper presence on average leads to some 440 additional panachage votes. Presence in broadcasting also has an average positive effect for an increase in one standard deviation, 0.9, but the lower end of the distribution dips into the negative, meaning that the effect is less consistent. Out of the social media variables, resonance on Facebook is, once again, the only notable effect. An increase in one standard deviation, 555.1, leads to around 178 additional panachage votes on average. Voting list rank is, once again, displaying a small negative effect: The lower the candidates are on the voting list, the fewer panachage votes they receive.

The results only partly support hypothesis 3. Even though some of the brute force variables do have a non-negligible effect, only presence in newspapers has an effect that can be regarded as substantial. The average amount of panachage votes per candidate is around 8400 , and the standard deviation is around 16800 . Within such a context, about 440 votes gained from an increase in one standard deviation 
of newspaper articles can be relevant. Similarly, resonance on Facebook can also have a smaller, but still substantial impact with an average of about 178 votes per an increase in one standard deviation of resonance.

\subsection{Hypothesis H4: Amount of cumulation votes}

In hypothesis $\mathrm{H} 4$, we posit that the brute force effects of mass media presence and social media activity will increase a candidate's cumulation votes. Before delving into the results, it is necessary to briefly explain why and how the amount of cumulation votes candidates receive can be, and almost certainly is, biased. In principle, every voter is allowed to cumulate votes for candidates, meaning that a voter is allowed to place one candidate on a voting list twice. Most parties have as many different candidates as they are allowed to have. In the Swiss federal election of 2015, each voting list in the canton of Zurich could contain up to 35 candidates, because Zurich occupies 35 seats in the lower house. Most parties had 35 different candidates on their voting lists. Some smaller ones, however, did not have 35 candidates, and some of those smaller parties put one or several candidates already twice on their list.

Cumulating the potential votes in this manner by putting a candidate's name twice on a voting list a priori is completely legal, since, in the end, if a voter decides not to change such a list, the voter has expressed his or her will to cumulate votes for the candidates in question. In principle, then, this type of cumulation is simply cumulation, nothing more. But in reality, this is a prototypical scenario where a prominent cognitive heuristic, the status quo bias (Fernandez and Rodrik 1991; Samuelson and Zeckhauser 1988), comes into play. The status quo bias is the observation that people tend to disproportionately favor not changing things over changing them. In the context of cumulation votes, it is highly probable that voters will also favor the status quo, which means that those candidates whose names are cumulated a priori are more likely to receive cumulation votes than candidates whose names are not cumulated a priori. The nature of this kind of $a$ priori cumulation is, in the end, a case of non-rational voting through nudging.

Nonetheless, it is worth to have a look at the estimation results, even if there is some bias present with the dependent variable. The results are summarized in Table 7.

Once again, incumbency has the strongest effect. On average, incumbents receive around 5812 additional cumulation votes. Furthermore, the presence both in broadcasting as well as in newspapers has a positive effect. On average, an increase in one standard distribution of broadcasting presence, 0.9 , leads to around 113 additional cumulation votes, and an increase in one standard deviation of newspaper presence, 5.3, leads to around 165 additional cumulation votes. Among the social media variable, only resonance on Facebook has a notable effect. An increase of one standard deviation of Facebook resonance, 555.1, leads to around 150 additional cumulation votes. Also, as with the previous models, voting list rank has a small negative effect. 
Table 7: Estimates of the fourth model, with the amount of cumulation votes as the dependent variable.

\begin{tabular}{lrccc}
\hline Parameter & Mean & $2.5 \%$ quantile & $97.5 \%$ quantile & $\hat{R}$ \\
\hline Presence - newspapers & 164.88 & 88.19 & 244.05 & 1.02 \\
Presence - broadcasting & 113.40 & 2.23 & 211.94 & 1.10 \\
Activity - Facebook & -9.49 & -32.84 & 16.67 & 1.00 \\
Resonance - Facebook & 149.69 & -8.19 & 272.69 & 1.02 \\
Activity - Twitter & 17.97 & -32.29 & 85.84 & 1.01 \\
Resonance - Twitter & -14.80 & -73.23 & 38.04 & 1.00 \\
Voting list rank & -58.42 & -69.78 & -47.44 & 1.00 \\
Incumbency & 5811.99 & 4222.20 & 7854.54 & 1.03 \\
Age & -6.92 & -18.85 & 5.00 & 1.00 \\
Gender (female) & 18.64 & -3.13 & 40.01 & 1.00
\end{tabular}

Note: The range between the $2.5 \%$ and $97.5 \%$ quantiles is the so-called $95 \%$ credible interval (CI). Given the data, there is a $95 \%$ probability that the parameter of interest lies in this range.

The results do not support hypothesis 4 . The average amount of cumulation votes each candidate received is around 7400 , with a standard deviation of around 15100. The brute force effects of mass media presence and social media activity are all too small to be considered substantial. The strongest effect, an additional 165 votes, on average, by an increase in one standard deviation in newspaper presence (5.3 articles), is fairly small.

\subsection{Hypothesis H5: The force is stronger with mass media presence}

In our final hypothesis $\mathrm{H} 5$, we posit that the brute force effects of mass media presence are stronger than the brute force effects of social media activity. Given the results of the models described above, this seems to be the case. From the two variables of mass media presence, the presence in newspaper articles displays a consistent effect: Newspaper presence slightly increases candidates' odds of getting elected, and it increases the amount of total votes, the amount of panachage votes, as well as the amount of cumulation votes. There are also signs that presence in broadcasting has a positive effect, but the effect is, overall, somewhat weaker and less consistent than newspaper presence. Among the social media variables, only resonance on Facebook has produced relevant effects. But those effects are consistent and, for one model, the total amount of votes, Facebook resonance is even the strongest brute force effect. 


\section{Discussion: Brute and forceful, but not quite as expected}

The results of our analysis of the 2015 Swiss federal election, naturally, only paint a partial picture of brute force effects of candidates' mass media presence and social media activity. But that picture, we believe, is mostly plausible, and at least to some degree generalizable beyond the context of Swiss elections.

We started out with the general expectation that brute force effects are minor effects. Our results are very much compatible with that assumption: Even in scenarios where brute force effects are potentially maximized, they are unlikely to completely make or break an election. But at the same time, they are also non-trivial. Within a given voting list, candidates sometimes receive very similar amounts of votes, and a several hundred to a few thousand potential additional or missing - votes can make a difference in terms of electoral prospects if several candidates are competing closely.

However, the impact of brute force effects did not play out exactly as we expected in our hypotheses. In the context of the first hypothesis, we actually observed an effect, namely that of presence in newspapers, that does constitute a non-trivial impact. The results for the second hypothesis are surprising: Contrary to our expectation, the effects of mass media presence and social media activity were substantial. Specifically, the effects of newspaper presence and of Facebook resonance are strong. The results for the third hypothesis were consistent with our expectation. Specifically, the effects of newspaper presence and Facebook resonance have a relatively strong impact. The results for the fourth hypothesis, however, only partly support the hypothesis. Mass media presence and social media activity does have a number of consistent effects, but they have, at best, a modest impact. The final hypothesis was supported by the results. Overall, the effects of mass media presence are stronger and more consistent than the effects of social media activity.

Overall, and contrary to our expectations, possible brute force effects are not only present for the amount of panachage and cumulation votes, but also for the total amount of votes as well as the odds of getting elected. Those effects are only present for mass media presence, not for social media activity and resonance. This forms an important general insight of the present study: In the context of brute force effects, traditional media still matter, and they matter a lot. That is not to say that social media is not important, both for candidates and for voters. But professional journalistic mass media still exert a centripetal force whereby large parts of society become informed. Consequently, it is unlikely that professional mass media will become obsolete for political campaigning anytime soon. It is important, we believe, to try and keep such a "global" perspective in mind when conducting research in the context of politics and social media. It is tantalizing to conduct research exclusively within the context of social media, not least because it is often easier to collect social media data than mass media data. However, 
social media should not be analyzed in total isolation, and, furthermore, electoral behavior should not be reduced to media effects, be they induced by mass or by social media. That is precisely the rationale of our concept of brute force effects, because they are only a minor, but a relevant part of voter behavior.

\subsection{Social media: Resonance, not direct activity, matters}

One of the most intriguing aspects of the results of this study is the unequal impact of different social media variables. Facebook activity, Twitter activity and Twitter resonance are, essentially, meaningless and inconsistent. However, Facebook resonance has a consistent and substantial effect. There are two possible conclusions that can be drawn from this result. First, in the Swiss context, Facebook might matter more than Twitter as a platform for political candidates. Facebook has far more monthly active users than Twitter in Switzerland (about 3.5 million compared to 0.7 million, Statista GmbH 2017). Second, and more importantly, resonance on social media might matter more than activity in general. This is, of course, rather plausible. A candidate might be very active on social media, but if she or he has no audience, then that activity will not, obviously, translate into votes. It is even possible that candidates who are "desperate" will be more active on social media, to no avail, since nobody is listening.

\subsection{The electoral Matthew effect}

In our models, the strongest predictor of electoral success was incumbency: Candidates who are sitting members of the lower house do much better, on average, than challengers. This electoral Matthew effect in the sense of $\operatorname{Pr}(e \mid i)>\operatorname{Pr}(e \mid c)$, where $e$ stands for being elected, $i$ for incumbent, and $c$ for challenger, is no big surprise. After all, we specifically included incumbency as an independent variable because it has been shown time and again that incumbency matters. How important, then, could incumbency be in the context of brute force effects? Specifically, could incumbency be a driver of mass media presence and social media activity? Indeed, there is ample evidence that the incumbency bonus extends to mass media presence (Hopmann, Vreese, and Albæk 2011; Green-Pedersen, Mortensen, and Thesen 2015). The potential impact of the incumbency effect in the context of brute force effects can thus be described as a two-step Matthew effect. First, incumbents receive more air time and more presence in newspapers on account of their prominence. Second, being more visible in the mass media, in turn, has an effect on voters, part of which consists of brute force effects.

The incumbency effect as a two-step Matthew effect is, to some degree, a double status quo bias. Incumbents enjoy a disproportionate amount of media coverage because they are incumbents, and in turn, incumbents' higher visibility as a brute force effect strengthens voters' general status quo bias as the preference for incumbents. Given the data of this study, such a two-step mechanism is conceivable: Incumbents commanded $55 \%$ of total candidate TV and radio presence, and $38 \%$ 
of total candidate newspaper presence - while being only a small minority of $3.3 \%$ within the total candidate pool.

\subsection{Limitations and future research}

Our study has a number of limitations. First, we have conducted our analysis only in the context of one election, and it is therefore impossible to say whether the results are generalizable in a temporal (future elections in the same political context) and geographical (elections in different contexts) manner.

A second major limitation is the question of how important the potential brute force effects are for different parts of the public. Not all people have the same mass media and social media repertoires and habits. It is therefore conceivable that a much clearer picture of brute force effects would emerge if they were studied directly by analyzing individual voting behavior instead of aggregated population-level votes. For example, the effects of social media activity might be much stronger for voters who are heavy users of social media and who rarely consume mass media.

Another limitation of this study is that we have condensed the analyzed time period into a cross-sectional data set. Looking at brute force effects with a timeseries design would allow to extend the analysis to effects of intermedia agendasetting: It is possible that candidate mass media presence has a relevant impact on their social media activity and resonance, and vice versa.

We encourage further research on the concept of brute force effects - with the present study, brute force effects have been explored only tentatively in the context of one single election. The general theoretical strategy we adopt in this study should be pursued further. That is not to say that all future research has to rely on exactly the same notions of bounded rationality, but we do think it necessary to embed features of biase-prone human cognition, such as brute force effects, within a more generalizable model of voter behavior.

That being said, we think there are two general ways future research could further explore brute force effects. The first prospect for future research is quasireplication in different political contexts. By this we simply mean studying potential brute force effects in a similar manner as we do presently, but for different political contexts. After all, not all political campaigns, not all voting systems, and not all mass media systems are the same. The second prospect for future research is research with different research designs. As explained above, one major limitation of our study is the fact that we did not have access to the micro-level of individual voting behavior. That is precisely what should be in future research, be it in the form of experimental or in the form of survey-type designs. Only then the exact share of non-rational voting influenced by brute force effects can be estimated (see Figure 1). 


\subsection{Normative implications}

The primary motivation for the present study is to put expectations that arise from theory to the empirical test. Given our model of bounded voter rationality and brute force effects as a form of non-rational voting behavior, we set out to analyze whether the effects we expected are present. From our results, however, some normative implications arise. Political decision-making by citizens should be as rational as possible, and non-rational voting behavior as the result of cognitive heuristics is therefore a normative problem. Consequently, brute force effects are also a problem. How much of a problem? Not a great one, for at least two reasons.

First, we imagine brute force effects, conceptually, as only a minor part of nonrational voting. Non-rational voting in general might be a problem (quantifying the overall amount of irrational behavior in voting is way beyond the scope of the present paper), but brute force effects of mass media presence and social media activity are only a minor slice of that problem. Furthermore, our empirical results support our theoretical assumption that brute force effects are, at most, moderate effects.

Second, brute force effects are likely to be universal effects, since they are a consequence of cognitive heuristics. Cognitive heuristics are a universal property of human cognition, and therefore, the magnitude of brute force effects should be more or less equally distributed among the population. That might hardly sound like something to take solace in. But if brute force effects exist, then it is normatively preferable that they be present and weak in the general population rather than disproportionately concentrated within some population segments or strata. 


\section{References}

Alford, John R. and John R. Hibbing (1981). "Increased Incumbency Advantage in the House". In: The Journal of Politics 43.04, pp. 1042-1061. DOI: 10.2307/21 30188.

Ansolabehere, Stephen and James M. Snyder (2002). "The Incumbency Advantage in U.S. Elections: An Analysis of State and Federal Offices, 1942-2000". In: Election Law Journal: Rules, Politics, and Policy 1.3, pp. 315-338. DOI: 10.10 89/153312902760137578.

Anstead, Nick and Ben O'Loughlin (2015). "Social Media Analysis and Public Opinion: The 2010 UK General Election". In: Journal of Computer-Mediated Communication 20.2, pp. 204-220. DOI: 10.1111/jcc4.12102.

Baker, Reg, J. Michael Brick, Nancy A. Bates, Mike Battaglia, Mick P. Couper, Jill A. Dever, Krista J. Gile, and Roger Tourangeau (2013). "Summary Report of the AAPOR Task Force on Non-probability Sampling". In: Journal of Survey Statistics and Methodology 1.2, pp. 90-143. DOI: 10.1093/jssam/smt008.

Bar-Hillel, Maya (1980). "The base-rate fallacy in probability judgments". In: Acta Psychologica 44.3, pp. 211-233. DOI: 10.1016/0001-6918(80)90046-3.

Bates, Douglas, Martin Mächler, Ben Bolker, and Steve Walker (2014). "Fitting Linear Mixed-Effects Models using lme4". In: arXiv:1406.5823 [stat].

Bennett, W. Lance and Shanto Iyengar (2008). "A New Era of Minimal Effects? The Changing Foundations of Political Communication". In: Journal of Communication 58.4, pp. 707-731. DOI: $10.1111 / \mathrm{j} .1460-2466.2008 .00410 . \mathrm{x}$.

Bessi, Alessandro and Emilio Ferrara (2016). "Social bots distort the 2016 U.S. Presidential election online discussion". In: First Monday 21.11.

Black, Duncan (1948). "On the Rationale of Group Decision-making". In: Journal of Political Economy 56.1, pp. 23-34.

Browne, William J. and David Draper (2006). "A comparison of Bayesian and likelihood-based methods for fitting multilevel models". In: Bayesian Analysis 1.3, pp. 473-514. DOI: $10.1214 / 06-$ BA117.

Bryan, Mark L. and Stephen P. Jenkins (2016). "Multilevel Modelling of Country Effects: A Cautionary Tale". In: European Sociological Review 32.1, pp. 3-22. DOI: $10.1093 /$ esr/jcv059.

Bürkner, Paul-Christian (2017). brms: Bayesian Regression Models using Stan.

Carpenter, Bob, Andrew Gelman, Matthew Hoffman, Daniel Lee, Ben Goodrich, Michael Betancourt, Marcus Brubaker, Jiqiang Guo, Peter Li, and Allen Riddell (2017). "Stan: A Probabilistic Programming Language". In: Journal of Statistical Software 76.1, pp. 1-32. DOI: 10.18637/jss.v076.i01.

DiGrazia, Joseph, Karissa McKelvey, Johan Bollen, and Fabio Rojas (2013). "More Tweets, More Votes: Social Media as a Quantitative Indicator of Political Behavior". In: PLOS ONE 8.11, e79449. DOI: 10.1371/journal.pone.007944 9. 
Dolan, Kathleen (2008). "Is There a "Gender Affinity Effect" in American Politics? Information, Affect, and Candidate Sex in U.S. House Elections". In: Political Research Quarterly 61.1, pp. 79-89. DOI: 10.1177/1065912907307518.

Downs, Anthony (1957). "An Economic Theory of Political Action in a Democracy". In: Journal of Political Economy 65.2, pp. 135-150.

Erikson, Robert S. (1971). "The Advantage of Incumbency in Congressional Elections". In: Polity 3.3, pp. 395-405. DOI: 10.2307/3234117.

Fernandez, Raquel and Dani Rodrik (1991). "Resistance to Reform: Status Quo Bias in the Presence of Individual- Specific Uncertainty". In: The American Economic Review 81.5, pp. 1146-1155.

Ferree, Myra Marx (2002). Shaping Abortion Discourse: Democracy and the Public Sphere in Germany and the United States. Cambridge University Press. ISBN: 978-0-521-79384-1.

fög-Forschungsbereich Öffentlichkeit und Gesellschaft (2015). Jahrbuch 2015 Qualität der Medien. Basel: Schwabe Basel. ISBN: 978-3-7965-3437-9.

Gayo-Avello, Daniel (2012). "I Wanted to Predict Elections with Twitter and all I got was this Lousy Paper" - A Balanced Survey on Election Prediction using Twitter Data". In: arXiv:1204.6441 [physics].

- (2013). "A Meta-Analysis of State-of-the-Art Electoral Prediction From Twitter Data". In: Social Science Computer Review 31.6, pp. 649-679. DOI: 10.1177/0 894439313493979.

Gelman, Andrew and Jennifer Hill (2006). Data Analysis Using Regression and Multilevel/Hierarchical Models. Cambridge ; New York: Cambridge University Press. ISBN: 978-0-521-68689-1.

Gelman, Andrew and Gary King (1993). "Why Are American Presidential Election Campaign Polls So Variable When Votes Are So Predictable?" In: British Journal of Political Science 23.04, pp. 409-451. DOI: 10.1017/S0007123400006682.

Gelman, Andrew and Donald B. Rubin (1992). "Inference from Iterative Simulation Using Multiple Sequences". In: Statistical Science 7.4, pp. 457-472. DOI: 10.12 14/ss/1177011136.

Gibson, Rachel K. and Ian McAllister (2011). "Do Online Election Campaigns Win Votes? The 2007 Australian "YouTube" Election". In: Political Communication 28.2, pp. 227-244. DOI: 10.1080/10584609.2011.568042.

Green, Donald P. and Alan S. Gerber (2015). Get Out the Vote: How to Increase Voter Turnout. Washington, D.C: Brookings Institution Press. ISBN: 978-0-81572568-8.

Green-Pedersen, Christoffer, Peter B. Mortensen, and Gunnar Thesen (2015). "The Incumbency Bonus Revisited: Causes and Consequences of Media Dominance". In: British Journal of Political Science FirstView, pp. 1-18. DOI: 10.1017/S00 07123415000022 .

Habermas, Jürgen (2006). "Political Communication in Media Society: Does Democracy Still Enjoy an Epistemic Dimension? The Impact of Normative Theory 
on Empirical Research1". In: Communication Theory 16.4, pp. 411-426. DOI: $10.1111 / \mathrm{j} .1468-2885.2006 .00280 . \mathrm{x}$.

Hansen, Jochim and Michaela Wänke (2009). "Liking What's Familiar: The Importance of Unconscious Familiarity in the Mere-Exposure Effect". In: Social Cognition 27.2, pp. 161-182. DOI: 10.1521/soco.2009.27.2.161.

Hansen, Kasper M. and Karina Kosiara-Pedersen (2014). "Cyber-Campaigning in Denmark: Application and Effects of Candidate Campaigning". In: Journal of Information Technology \& Politics 11.2, pp. 206-219. DOI: 10.1080/19331681 .2014 .895476 .

Hansen, Kasper M. and Rasmus Tue Pedersen (2014). "Campaigns Matter: How Voters Become Knowledgeable and Efficacious During Election Campaigns". In: Political Communication 31.2, pp. 303-324. DOI: 10.1080/10584609.2013.81 5296.

Harmon-Jones, Eddie and John J. B. Allen (2001). "The Role of Affect in the Mere Exposure Effect: Evidence from Psychophysiological and Individual Differences Approaches". In: Personality and Social Psychology Bulletin 27.7, pp. 889-898. DOI: $10.1177 / 0146167201277011$.

Ho, Daniel E. and Kosuke Imai (2008). "Estimating Causal Effects of Ballot Order from a Randomized Natural Experiment The California Alphabet Lottery, 1978-2002". In: Public Opinion Quarterly 72.2, pp. 216-240. DOI: 10.1093 /poq/nfn018.

Hoekstra, Rink, Richard D. Morey, Jeffrey N. Rouder, and Eric-Jan Wagenmakers (2014). "Robust misinterpretation of confidence intervals". In: Psychonomic Bulletin \& Review 21.5, pp. 1157-1164. DOI: 10.3758/s13423-013-0572-3.

Hogan, Robert E. (2004). "Challenger Emergence, Incumbent Success, and Electoral Accountability in State Legislative Elections". In: Journal of Politics 66.4, pp. 1283-1303. DOI: $10.1111 / \mathrm{j} .0022-3816.2004 .00300 . \mathrm{x}$.

Hopmann, David Nicolas, Rens Vliegenthart, Claes De Vreese, and Erik Albæk (2010). "Effects of Election News Coverage: How Visibility and Tone Influence Party Choice". In: Political Communication 27.4, pp. 389-405. DOI: 10.1080/1 0584609.2010 .516798$.

Hopmann, David Nicolas, Claes H. de Vreese, and Erik Albæk (2011). "Incumbency Bonus in Election News Coverage Explained: The Logics of Political Power and the Media Market". In: Journal of Communication 61.2, pp. 264-282. DOI: $10.1111 / \mathrm{j} .1460-2466.2011 .01540 . \mathrm{x}$.

Iyengar, Shanto, Helmut Norpoth, and Kyu S. Hahn (2004). "Consumer Demand for Election News: The Horserace Sells". In: Journal of Politics 66.1, pp. 157-175. DOI: $10.1046 / j .1468-2508.2004 .00146 . x$.

Jacobs, Kristof and Niels Spierings (2016). "Saturation or maturation? The diffusion of Twitter and its impact on preference voting in the Dutch general elections of 2010 and 2012". In: Journal of Information Technology 85 Politics 13.1, pp. 1-21. DOI: $10.1080 / 19331681.2015 .1131652$. 
Jones, Bryan D. (1999). "Bounded Rationality". In: Annual Review of Political Science 2.1, pp. 297-321. DOI: 10.1146/annurev .polisci.2.1.297.

Juárez, Miguel A. and Mark F. J. Steel (2010). "Model-Based Clustering of NonGaussian Panel Data Based on Skew-t Distributions". In: Journal of Business $\&$ Economic Statistics 28.1, pp. 52-66. DOI: 10.1198/jbes.2009.07145.

Jungherr, Andreas (2013). "Tweets and Votes, a Special Relationship: The 2009 Federal Election in Germany". In: Proceedings of the 2Nd Workshop on Politics, Elections and Data. PLEAD '13. New York, NY, USA: ACM, pp. 5-14. ISBN: 978-1-4503-2418-2. DOI: 10.1145/2508436.2508437.

- (2016). "Twitter use in election campaigns: A systematic literature review". In: Journal of Information Technology \&6 Politics 13.1, pp. 72-91. DOI: 10.1080/1 9331681.2015 .1132401$.

Kaplan, Andreas M. and Michael Haenlein (2010). "Users of the world, unite! The challenges and opportunities of Social Media". In: Business Horizons 53.1, pp. 59-68. DOI: 10.1016/j . bushor.2009.09.003.

Koppell, Jonathan GS and Jennifer A. Steen (2004). "The Effects of Ballot Position on Election Outcomes". In: Journal of Politics 66.1, pp. 267-281. DOI: 10.1046 /j.1468-2508.2004.00151.x.

Kreiss, Daniel (2015). "Digital Campaigning". In: Handbook of Digital Politics. Ed. by Stephen Coleman and Deen Freelon. Cheltenham, UK ; Northampton, MA, USA: Edward Elgar Pub, pp. 118-135. ISBN: 978-1-78254-875-1.

Kruikemeier, Sanne (2014). "How political candidates use Twitter and the impact on votes". In: Computers in Human Behavior 34, pp. 131-139. DOI: 10.1016 /j.chb.2014.01.025.

Kruschke, John K. (2014). Doing Bayesian Data Analysis, Second Edition: A Tutorial with R, JAGS, and Stan. Boston: Academic Press. ISBN: 978-0-12405888-0.

Lange, Kenneth L., Roderick J. A. Little, and Jeremy M. G. Taylor (1989). "Robust Statistical Modeling Using the t Distribution". In: Journal of the American Statistical Association 84.408, pp. 881-896. DOI: 10.1080/01621459.1989.104 78852.

Marcinkowski, Frank and Julia Metag (2013). "Lassen sich mit dem Internet Wählerstimmen gewinnen?" In: Publizistik 58.1, pp. 23-44. DOI: 10.1007/s116 16-013-0168-y.

Mcdermott, Monika L. (1998). "Race and Gender Cues in Low-Information Elections". In: Political Research Quarterly 51.4, pp. 895-918. DOI: 10.1177/10659 1299805100403.

Metaxas, P.T., E. Mustafaraj, and D. Gayo-Avello (2011). "How (Not) to Predict Elections". In: 2011 IEEE Third International Conference on Privacy, Security, Risk and Trust (PASSAT) and 2011 IEEE Third Inernational Conference on Social Computing (SocialCom), pp. 165-171. DOI: 10.1109/PASSAT/SocialCom. 2011.98. 
Miller, Joanne M. and Jon A. Krosnick (1998). "The Impact of Candidate Name Order on Election Outcomes". In: The Public Opinion Quarterly 62.3, pp. 291330.

Morey, Richard D., Rink Hoekstra, Jeffrey N. Rouder, Michael D. Lee, and Eric-Jan Wagenmakers (2016). "The fallacy of placing confidence in confidence intervals". In: Psychonomic Bulletin \& Review 23.1, pp. 103-123. DOI: 10.3758/s13423015-0947-8.

Mullainathan, Sendhil and Richard H. Thaler (2000). Behavioral Economics. Working Paper 7948. National Bureau of Economic Research.

Nadeau, Richard, Neil Nevitte, Elisabeth Gidengil, and André Blais (2008). "Election Campaigns as Information Campaigns: Who Learns What and Does it Matter?" In: Political Communication 25.3, pp. 229-248. DOI: 10.1080/1058460080219 7269 .

Nickerson, David W. (2006). "Volunteer Phone Calls Can Increase Turnout Evidence From Eight Field Experiments". In: American Politics Research 34.3, pp. 271292. DOI: $10.1177 / 1532673 \times 05275923$.

- (2007). "Quality Is Job One: Professional and Volunteer Voter Mobilization Calls". In: American Journal of Political Science 51.2, pp. 269-282. DOI: 10.11 $11 / j .1540-5907.2007 .00250 . x$.

Nimmo, Dan D. (2001). The Political Persuaders: The Techniques of Modern Election Campaigns. New Brunswick, N.J: Transaction Publishers. ISBN: 978-07658-0613-0.

Petrocik, John R. (1996). "Issue Ownership in Presidential Elections, with a 1980 Case Study". In: American Journal of Political Science 40.3, pp. 825-850.

Piliavin, Jane Allyn (1987). "Age, Race, and Sex Similarity to Candidates and Voting Preference1". In: Journal of Applied Social Psychology 17.4, pp. 351-368. DOI: $10.1111 / \mathrm{j} .1559-1816.1987 . \mathrm{tb00318} . \mathrm{x}$.

Prior, Markus (2007). Post-Broadcast Democracy: How Media Choice Increases Inequality in Political Involvement and Polarizes Elections. New York: Cambridge University Press. ISBN: 978-0-521-67533-8.

R Core Team (2015). R: A Language and Environment for Statistical Computing. Vienna, Austria.

Rohrschneider, Robert (2002). "Mobilizing versus chasing: how do parties target voters in election campaigns?" In: Electoral Studies 21.3, pp. 367-382. DOI: 10.1016/S0261-3794(00)00044-5.

Samuelson, William and Richard Zeckhauser (1988). "Status quo bias in decision making". In: Journal of Risk and Uncertainty 1.1, pp. 7-59. DOI: 10.1007/BF0 0055564.

Scheufele, Dietram A. and David Tewksbury (2007). "Framing, Agenda Setting, and Priming: The Evolution of Three Media Effects Models". In: Journal of Communication 57.1, pp. 9-20. 
Seidman, Steven A. (2008). Posters, Propaganda, and Persuasion in Election Campaigns Around the World and Through History. Peter Lang. ISBN: 978-08204-8616-1.

Shepsle, Kenneth A. (2010). Analyzing Politics: Rationality, Behavior, and Instititutions. W W Norton \& Company Incorporated. ISBN: 978-0-393-93507-3.

Sigelman, Lee and Carol K. Sigelman (1982). "Sexism, Racism, and Ageism in Voting Behavior: An Experimental Analysis". In: Social Psychology Quarterly 45.4, pp. 263-269. DOI: 10.2307/3033922.

Simon, Herbert A. (1955). "A Behavioral Model of Rational Choice". In: The Quarterly Journal of Economics 69.1, pp. 99-118. DOI: 10.2307/1884852.

Smith, Timothy Hallam (2013). "Are you sitting comfortably? Estimating incumbency advantage in the UK: 1983-2010 - A research note". In: Electoral Studies 32.1, pp. 167-173. DOI: 10.1016/j.electstud.2012.12.002.

Spierings, Niels and Kristof Jacobs (2014). "Getting Personal? The Impact of Social Media on Preferential Voting". In: Political Behavior 36.1, pp. 215-234. DOI: $10.1007 / \mathrm{s} 11109-013-9228-2$.

Statista GmbH (2017). Social Media in der Schweiz. Tech. rep. Hamburg, Germany: Statista GmbH.

Stegmueller, Daniel (2013). "How Many Countries for Multilevel Modeling? A Comparison of Frequentist and Bayesian Approaches". In: American Journal of Political Science 57.3, pp. 748-761. DOI: 10.1111/ajps.12001.

Sunstein, Cass R. (2014). Why Nudge?: The Politics of Libertarian Paternalism. Yale University Press. ISBN: 978-0-300-20692-0.

Thaler, Richard H. and Cass R. Sunstein (2009). Nudge: Improving Decisions About Health, Wealth, and Happiness. New York: Penguin Books. ISBN: 978-014-311526-7.

Verhulst, Brad, Milton Lodge, and Howard Lavine (2010). "The Attractiveness Halo: Why Some Candidates are Perceived More Favorably than Others". In: Journal of Nonverbal Behavior 34.2, pp. 111-117. DOI: 10.1007/s10919-009-0084-z.

Zajonc, Robert B. (1968). "ATTITUDINAL EFFECTS OF MERE EXPOSURE". In: Journal of Personality and Social Psychology 9.2, Pt.2, pp. 1-27. DOI: $10.1037 / \mathrm{h} 0025848$.

- (2001). "Mere Exposure: A Gateway to the Subliminal". In: Current Directions in Psychological Science 10.6, pp. 224-228. DOI: 10.1111/1467-8721.00154.

Zhang, Zhiyong, Keke Lai, Zhenqiu Lu, and Xin Tong (2013). "Bayesian Inference and Application of Robust Growth Curve Models Using Student's t Distribution". In: Structural Equation Modeling: A Multidisciplinary Journal 20.1, pp. 47-78. DOI: $10.1080 / 10705511.2013 .742382$. 


\section{A Media sample}

The television and radio shows as well as the newspaper titles analyzed in the present study are summarized in Table 8.

Table 8: Media sample.

\begin{tabular}{llll}
\hline Medium type & Title & Geographic focus & Description \\
\hline Television & TalkTäglich & Regional & Daily political talk show \\
& SonnTalk & Regional & Weekly political talk show \\
& ZüriNews & Regional & Daily news show \\
& Tagesschau & National & Daily news show \\
& 10 vor 10 & National & Daily news show \\
& Arena & National & Weekly political talk show \\
\hline \multirow{2}{*}{ Radio } & Echo der Zeit & National & Daily news show \\
& Regionaljournal & Regional & Daily news show \\
& Rendez-vous & National & Daily news show \\
\hline Newspaper & Tages-Anzeiger & National & Daily newspaper \\
& Neue Zürcher Zeitung & National & Daily newspaper \\
& Blick & National & Daily newspaper \\
& Blick am Abend & National \& regional & Daily newspaper \\
& 20 Minuten & National \& regional & Daily newspaper \\
& SonntagsZeitung & National & Weekly newspaper \\
& NZZ am Sonntag & National & Weekly newspaper \\
& SonntagsBlick & National & Weekly newspaper \\
& Zürcher Oberländer & Regional & Daily newspaper \\
Zürcher Unterländer & Regional & Daily newspaper \\
& Zürichsee-Zeitung & Regional & Daily newspaper \\
& Der Landbote & Regional & Daily newspaper \\
\hline
\end{tabular}

The newspapers "Blick am Abend" and "20 Minuten" are distributed nationally, but in regional editions. We analyzed the Zurich editions in our sample.

The newspaper titles in the sample account for around $77 \%$ of total newspaper circulation in the canton of Zurich, according to a non-profit corporation that collects and verifies data an newspaper circulation (_ wemf_2015). All newspapers with medium and major circulation (75000 and more) in the canton of Zurich are contained in the sample, with the exception of the "Tagblatt der Stadt Zürich", which is not focused on politics. The selection criteria for the television and radio titles are less straightforward. The selection of the television shows was pragmatic: We have selected all regional and national news shows and political talk shows that are available in the canton of Zurich. This resulted in a number of public broadcasting news shows and political talk shows ("Tagesschau", "10vor10", "Arena"). There is only one regional television channel with political news content, "Tele 
Züri", and we have analyzed all news shows and political talk shows on that channel. In the case of radio, we have only selected news shows on public broadcasting, one of which focuses on regional content. Private radio stations in the canton of Zurich are less listened to than public radio stations, and the amount and duration news shows on private radio stations is kept to or near the regulatory minimum (fög-Forschungsbereich Öffentlichkeit und Gesellschaft 2015). 


\section{B Posterior distributions of the estimates}

\section{B.1 Posterior distributions of the estimates of the first model}

Figure 2: Posterior probability densities of the parameter estimates for the first model. The dependent variable is the dichotomous election outcome of being elected or not.
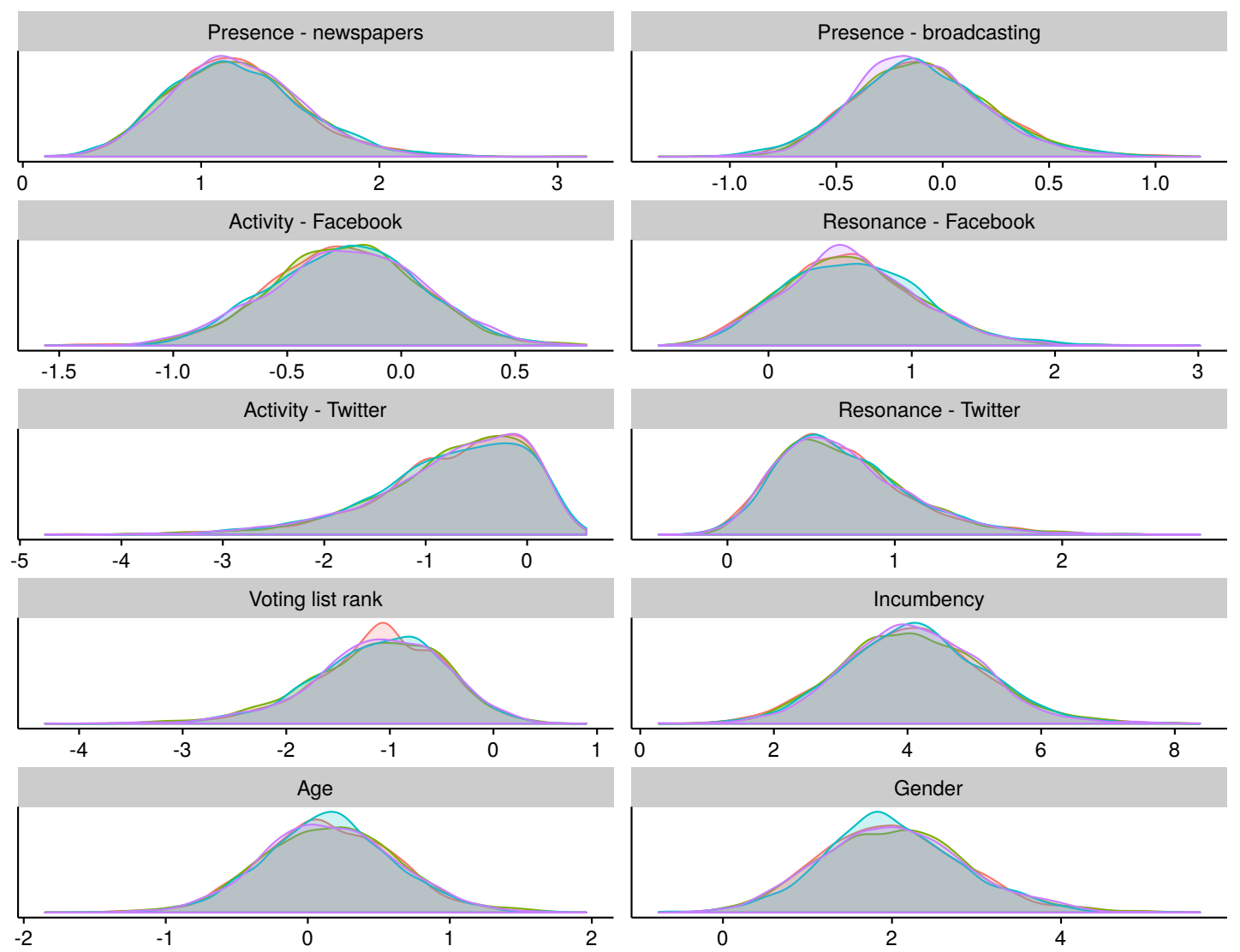

Note: The different colors represent the four sampling chains; the better the overlap of the four chains, the better the model convergence. The distribution shows the relative proportion of samples that estimate the effect at some value, as depicted on the x-axis of the parameter estimates. 


\section{B.2 Posterior distributions of the estimates of the second model}

Figure 3: Posterior probability densities of the parameter estimates for the second model. The dependent variable is the total number of votes.
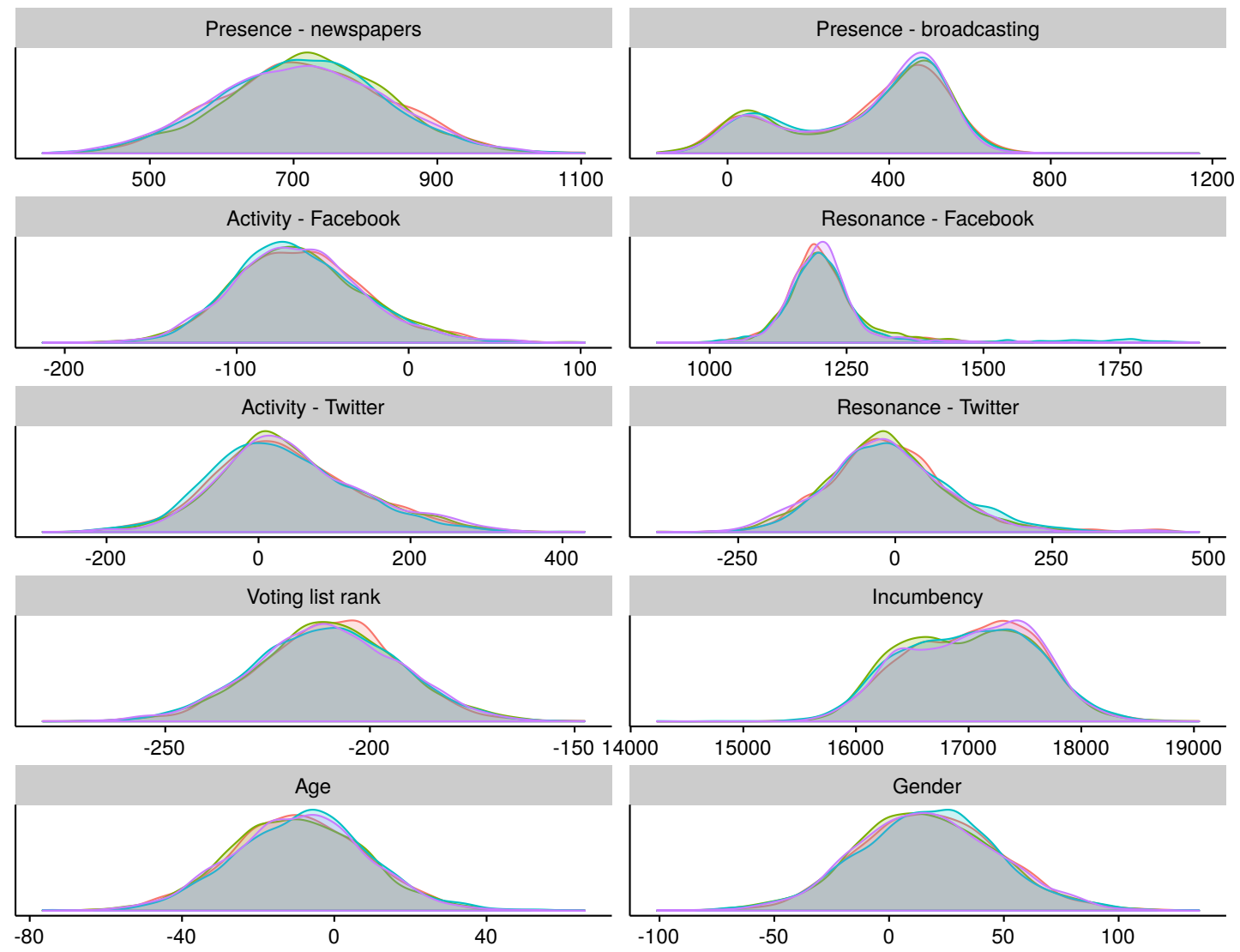

Note: The different colors represent the four sampling chains; the better the overlap of the four chains, the better the model convergence. The distribution shows the relative proportion of samples that estimate the effect at some value, as depicted on the $x$-axis of the parameter estimates. 


\section{B.3 Posterior distributions of the estimates of the third model}

Figure 4: Posterior probability densities of the parameter estimates for the third model. The dependent variable is the number of panachage votes.
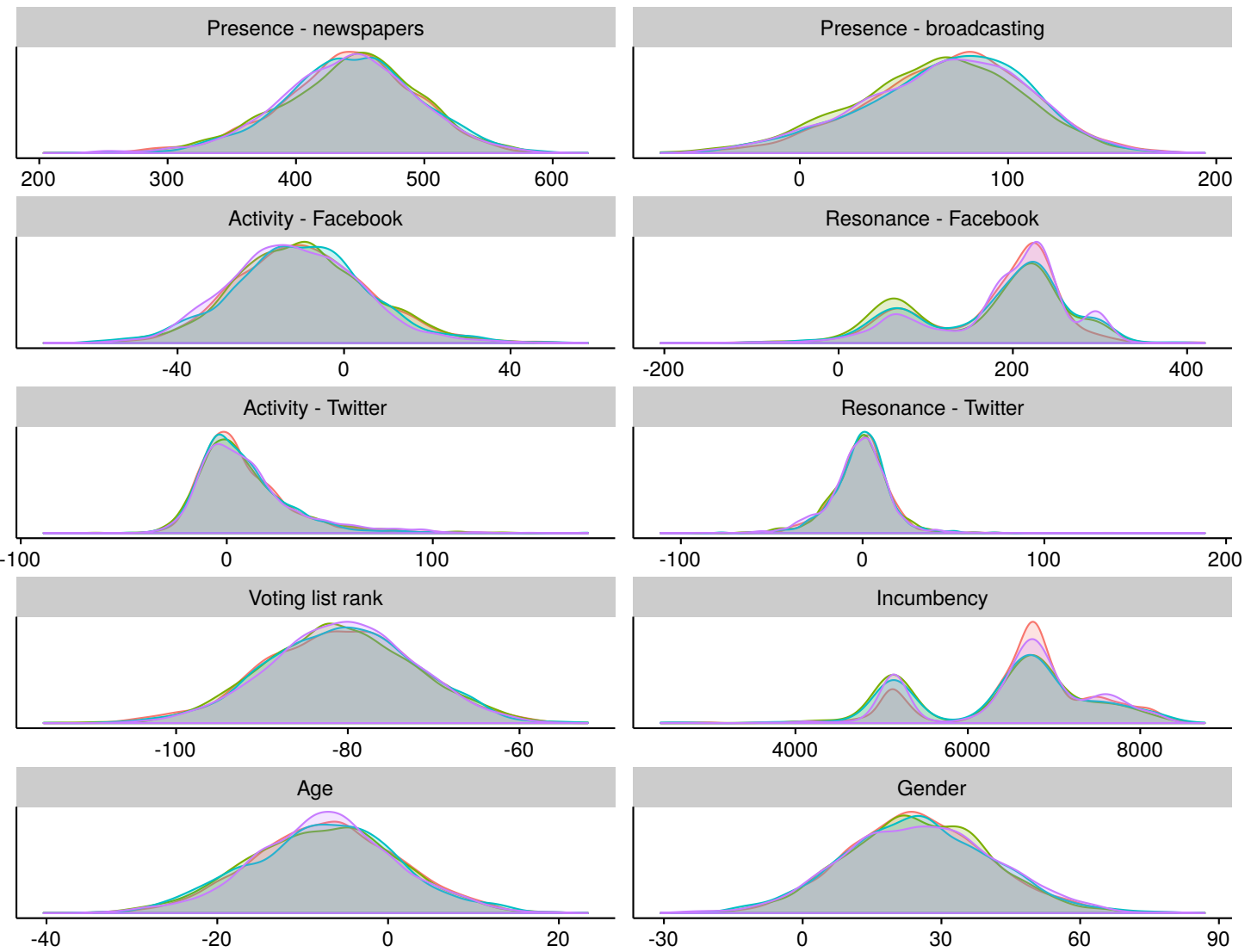

Note: The different colors represent the four sampling chains; the better the overlap of the four chains, the better the model convergence. The distribution shows the relative proportion of samples that estimate the effect at some value, as depicted on the $x$-axis of the parameter estimates. The distributions for resonance on Facebook and for incumbency suggest a bimodal effect. 


\section{B.4 Posterior distributions of the estimates of the fourth model}

Figure 5: Posterior probability densities of the parameter estimates for the fourth model. The dependent variable is the number of cumulation votes.
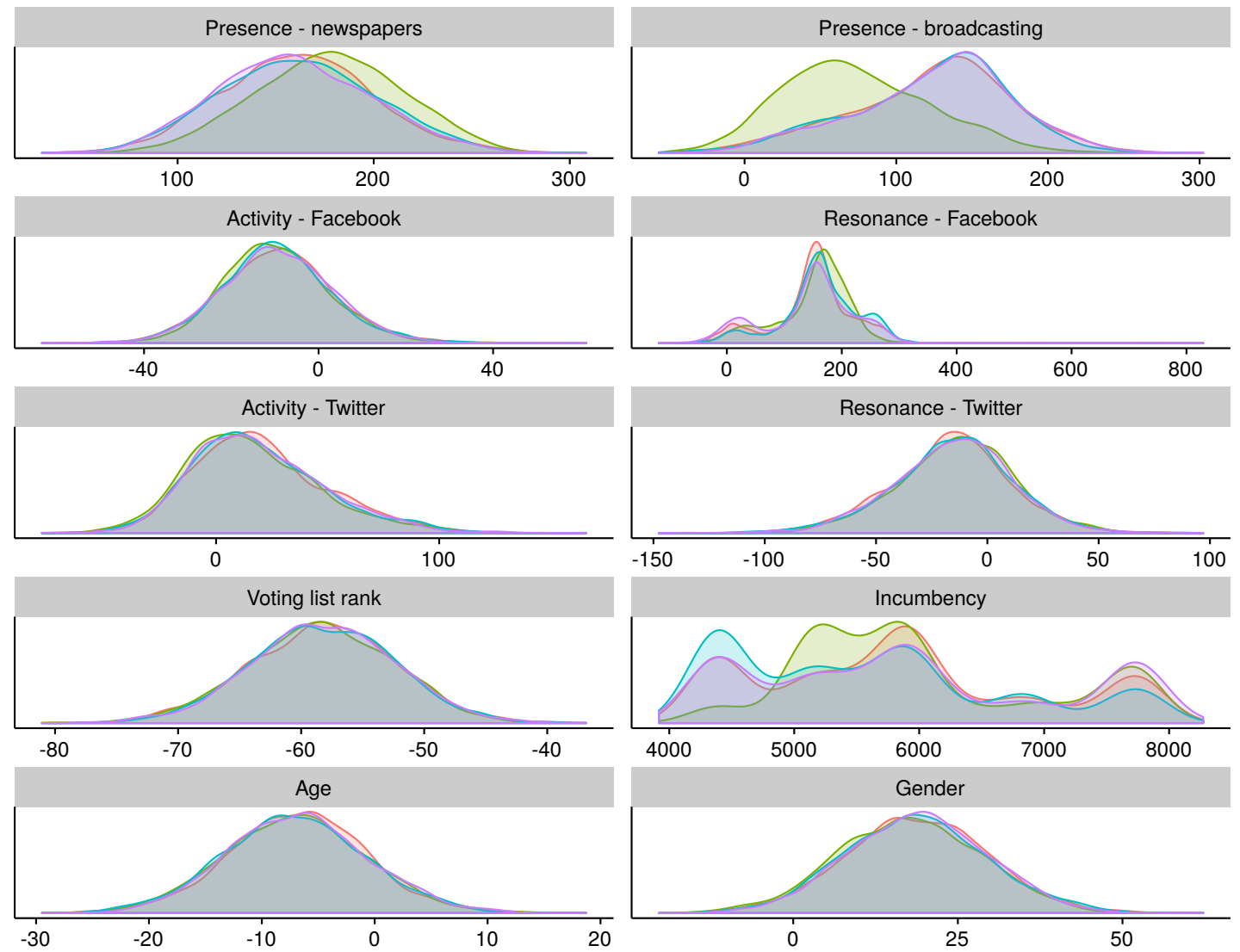

Note: The different colors represent the four sampling chains; the better the overlap of the four chains, the better the model convergence. The distribution shows the relative proportion of samples that estimate the effect at some value, as depicted on the $x$-axis of the parameter estimates. Presence in broadcasting has one divergent chain, which potentially suggests a bimodal effect. The distribution for incumbency is multimodal. The general range of the effect, between around 4000 and 8000 votes, is plausible. 


\section{Comparison of frequentist and Bayesian param- eter estimates}

In this section, we compare frequentist and Bayesian parameter estimates. More specifically, we present the frequentist point estimates estimated with the $\mathrm{R}$ package lme4 (Bates et al. 2014) in tabular form with the estimates of the four Bayesian models presented in our study. In addition, for models two to four, we present the mean Bayesian estimates for our models two to four, but with the normal distribution as a sampling distribution instead of student's t distribution. The frequentist point estimates and the Bayesian mean estimates using the normal distribution are quite similar to one another, whereas the estimates of the models with student's t distribution are slightly different (smaller, for the most part). This demonstrates the advantage of student's $t$ distribution for data that contains outliers.

Table 9: Comparison of frequentist and Bayesian estimates for model one, with being elected into office as the dependent variable.

\begin{tabular}{lcc}
\hline Parameter & Frequentist & Bayesian (Bernoulli) \\
\hline Presence - broadcasting & -0.14 & -0.10 \\
Presence - newspapers & 1.04 & 1.19 \\
Activity - Facebook & -0.23 & -0.24 \\
Resonance - Facebook & 0.38 & 0.58 \\
Activity - Twitter & -0.04 & -0.72 \\
Resonance Twitter & 0.31 & 0.68 \\
Voting list rank & -1.00 & -1.10 \\
Incumbency & 3.87 & 4.08 \\
Age & 0.16 & 0.15 \\
Gender (female) & 1.99 & 2.02 \\
\hline
\end{tabular}

Note: The distribution in the brackets is the sampling distribution used in the Bayesian model. 
Table 10: Comparison of frequentist and Bayesian estimates for model two, with the total amount of votes as the dependent variable.

\begin{tabular}{lccc}
\hline Parameter & Frequentist & Bayesian (normal) & Bayesian (student's t) \\
\hline Presence - broadcasting & -269.14 & -266.58 & 345.04 \\
Presence - newspapers & 3839.01 & 3842.17 & 714.69 \\
Activity - Facebook & 6.09 & 6.77 & -63.73 \\
Resonance - Facebook & 733.75 & 735.72 & 1213.55 \\
Activity - Twitter & -190.47 & -189.77 & 38.35 \\
Resonance Twitter & 126.38 & 125.53 & -9.48 \\
Voting list rank & -757.44 & -757.99 & -210.21 \\
Incumbency & 10936.72 & 10879.96 & 17012.03 \\
Age & -6.70 & -4.24 & -9.21 \\
Gender (female) & 429.35 & 430.84 & 16.88 \\
\hline
\end{tabular}

Note: The distributions in the brackets are the sampling distribution used in the Bayesian models.

Table 11: Comparison of frequentist and Bayesian estimates for model three, with the amount of panachage votes as the dependent variable.

\begin{tabular}{lccc}
\hline Parameter & Frequentist & Bayesian (normal) & Bayesian (student's t) \\
\hline Presence - broadcasting & 274.86 & 276.52 & 69.28 \\
Presence - newspapers & 1630.37 & 1629.64 & 441.39 \\
Activity - Facebook & 472.87 & 473.11 & -10.50 \\
Resonance - Facebook & 25.15 & 23.70 & 178.21 \\
Activity - Twitter & 12.78 & 12.72 & 8.81 \\
Resonance Twitter & 77.32 & 77.57 & -1.30 \\
Voting list rank & -205.69 & -206.10 & -80.82 \\
Incumbency & 7105.07 & 7091.28 & 6499.10 \\
Age & 5.60 & 5.84 & -7.43 \\
Gender (female) & 263.01 & 264.24 & 25.15 \\
\hline
\end{tabular}

Note: The distributions in the brackets are the sampling distribution used in the Bayesian models. 
Table 12: Comparison of frequentist and Bayesian estimates for model four, with the amount of cumulation votes as the dependent variable.

\begin{tabular}{lccc}
\hline Parameter & Frequentist & Bayesian (normal) & Bayesian (student's t) \\
\hline Presence - broadcasting & -536.22 & -536.51 & 113.40 \\
Presence - newspapers & 2189.78 & 2191.01 & 164.88 \\
Activity - Facebook & -456.73 & -455.90 & -9.49 \\
Resonance - Facebook & 700.39 & 699.74 & 149.69 \\
Activity - Twitter & -194.24 & -193.17 & 17.97 \\
Resonance Twitter & 34.42 & 34.39 & -14.80 \\
Voting list rank & -564.14 & -564.45 & -58.42 \\
Incumbency & 3739.42 & 3727.27 & 5811.99 \\
Age & -1.97 & -4.44 & -6.92 \\
Gender (female) & 190.58 & 190.94 & 18.64 \\
\hline
\end{tabular}

Note: The distributions in the brackets are the sampling distribution used in the Bayesian models. 


\section{Election results}

Figure 6 is a summary of the party-level election results.

Figure 6: Box plots for all parties with at least one elected candidate.

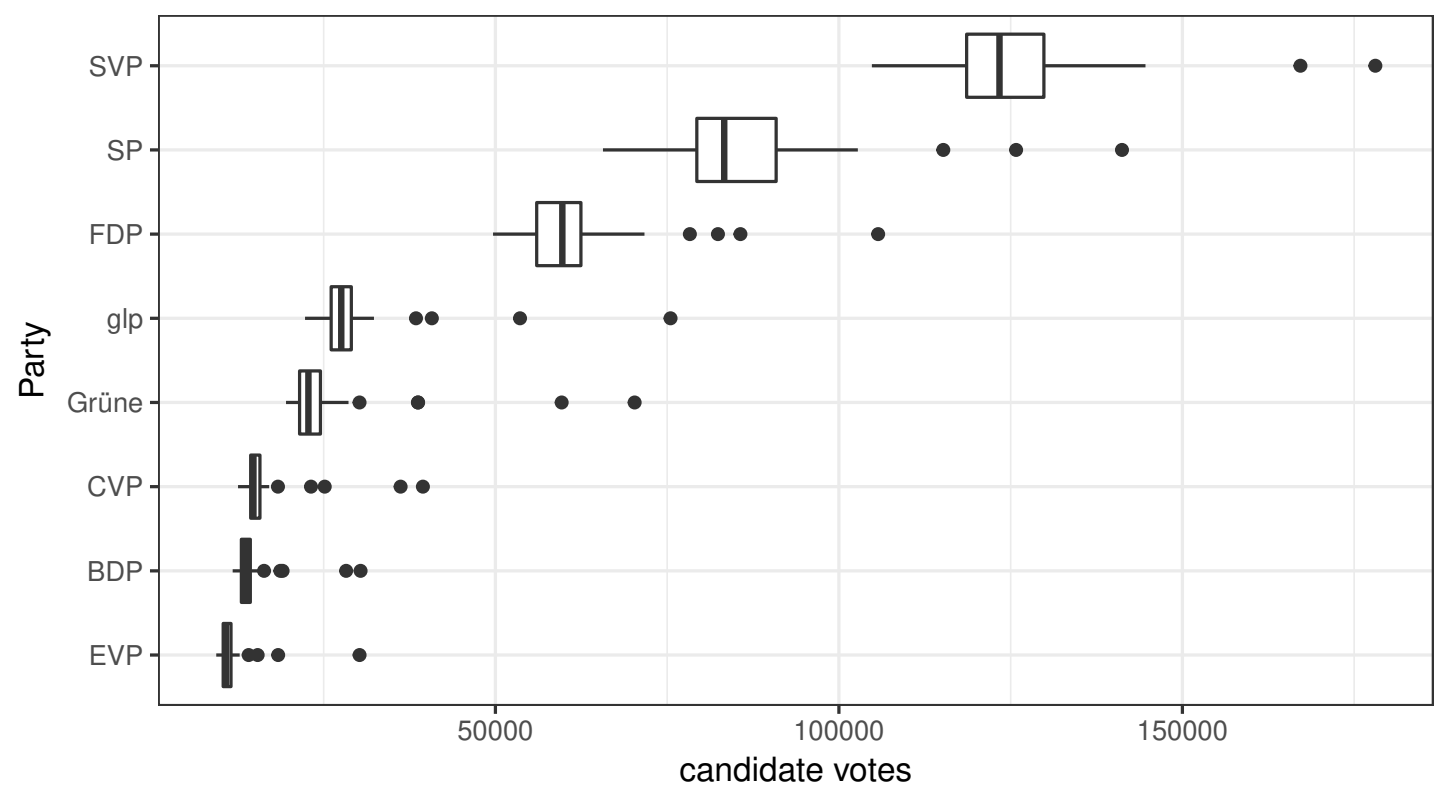

Note: We created box plots for all parties that have at least one elected candidate. The boxplots summarized the distribution of votes that individual candidates received in each party. 